\title{
Orientation control of intermediate-composition SiGe on insulator by low-temperature Al-induced crystallization
}

\author{
Mitsuki Nakata, ${ }^{1}$ Kaoru Toko, ${ }^{1, *}$ Noriyuki Saitoh, ${ }^{2}$ Noriko Yoshizawa, ${ }^{2}$ Takashi Suemasu ${ }^{1}$ \\ ${ }^{1}$ Institute of Applied Physics, University of Tsukuba, Tsukuba, Ibaraki 305-8573, Japan \\ ${ }^{2}$ Electron Microscope Facility, TIA, AIST, 16-1 Onogawa, Tsukuba 305-8569, Japan
}

\begin{abstract}
:
Metal-induced crystallization has allowed for high-quality Si and Ge thin films on insulators at low temperatures; however, there has been difficulty for SiGe alloys of intermediate compositions. Here we demonstrate a large-grained (> $100 \mu \mathrm{m}), 99 \%$ (111)-oriented $\mathrm{Si}_{0.4} \mathrm{Ge}_{0.6}$ layer on a glass substrate through layer exchange between $\mathrm{Al}$ and amorphous Si $0.4 \mathrm{Ge} 0.6$ layers. Slow annealing below $350{ }^{\circ} \mathrm{C}$ is a key to suppressing nucleation and facilitating lateral growth. The use of the (111)-oriented SiGe layers as epitaxial templates will pave the way for integrating various materials monolithically on three-dimensional Si large-scale integrated circuits and on multi-functional displays.
\end{abstract}

Keywords: Polycrystalline SiGe, Thin films, Crystal growth, Catalysis, Sputtering

${ }^{*}$ Corresponding author: Kaoru Toko

Institute of Applied Physics, University of Tsukuba,

1-1-1 Tennodai, Tsukuba, Ibaraki 305-8573, Japan

Phone: +81-29-853-5472, Fax: +81-29-853-5205

E-mail: toko@bk.tsukuba.ac.jp 
In the past few decades, SiGe-on-insulator (SGOI) structures have been widely investigated for use in thin-film transistors [1-4], thin-film solar cells [5,6], and on-chip optical interconnects $[7,8]$. A (111)-oriented SGOI is of particular interest because it works as a virtual substrate for III-V compound semiconductors $[9,10]$ and silicide materials [11-13]. For incorporating SGOI structures in inexpensive glass substrates or three-dimensional large-scale integrated circuits, low temperature process $\left(<500{ }^{\circ} \mathrm{C}\right)$ is required. In line with this, many growth techniques have been developed: chemical-vapor deposition [14-17], sputtering [18], laser annealing [19], and metal-induced crystallization (MIC) [20-22]. Among them, MIC is especially useful to lower the crystallization temperature of amorphous (a-) SiGe. The conventional MIC, however, resulted in polycrystalline (poly-) SGOI with randomly oriented small grains $(<1 \mu \mathrm{m})$.

For elemental Si [23-28] and Ge [29-33], large-grained, (111)-oriented layers on insulators have been achieved at low temperatures using MIC through "layer exchange". Several attempts have been made to fabricate high-quality SiGe alloys through layer exchange [34-41]. Large-grained $(\sim 10 \mu \mathrm{m})$, preferentially (111)-oriented SGOIs were achieved when the $\mathrm{Si}$ or Ge compositions were low $(<20 \%)$; however, the grain size and (111)-orientation fraction deteriorated as SiGe approached the intermediate compositions (20-80\%) [37,39].

We found that, in the previous studies, the annealing conditions (temperature and time) were almost the same as those for Si or Ge. Here we report the Al-induced layer exchange 
(ALILE) of an intermediate-composition SiGe focusing on the annealing temperature and time because those should be determined according to the SiGe composition [20]. Slow annealing below $350{ }^{\circ} \mathrm{C}$ results in a high-quality $\mathrm{Si}_{0.4} \mathrm{Ge}_{0.6}$ layer whose (111) orientation fraction $(99 \%)$ and grain size $(>100 \mu \mathrm{m})$ are comparable to those of $\mathrm{Si}$ and Ge layers formed by ALILE [29.32].

Figure 1 presents a schematic of the sample preparation process. A 50-nm-thick Al layer was prepared on $\mathrm{SiO}_{2}$ glass substrate, and then exposed to air for $30 \mathrm{~min}$ to form a native $\mathrm{AlO}_{x}$ membrane as diffusion-limiting layer [29,31]. A 50-nm-thick a-SiGe layer was then prepared in a $\mathrm{Si} / \mathrm{Ge}$ atomic ratio of 40:60, confirmed by a Rutherford Backscattering Spectrometry (RBS) analysis. All the depositions were carried out at room temperature using a radio frequency magnetron sputtering with Ar plasma. After that, the sample was annealed at $325-375{ }^{\circ} \mathrm{C}$ for $1-200 \mathrm{~h}$ in a $\mathrm{N}_{2}$ ambient for layer exchange growth. By removing the $\mathrm{Al}$ and $\mathrm{AlO}_{x}$ layers using an $\mathrm{HF}$ solution (HF: 1.5\%) for 1 min, bared SiGe layers were obtained, as representatively shown in the photograph in Figure 1.

Figure 2(a)-(d) show that the samples annealed at $335-375{ }^{\circ} \mathrm{C}$ have SiGe layers covering the substrates owing to finished layer exchange, while the $325{ }^{\circ} \mathrm{C}$ annealed sample is in the process of growing and has unreacted amorphous SiGe layers on the surface. The growth domains, shown by the dotted circles in Figure 2(a)-(d), expands with lowering the annealing temperature as with the ALILE of Si [29] and Ge [31]. From Raman scattering 
spectroscopy (wavelength: $532 \mathrm{~nm}$ ), spectra corresponding to SiGe crystals [20,35] were obtained for all the samples, as shown in Figure 2(e). The Ge compositions, estimated from the equation proposed by Mooney et al [42] were approximately $60 \%$ for all the samples, which is the same value as the initial a-SiGe layer.

The crystal orientation of the SiGe layers was evaluated using electron backscatter diffraction (EBSD). Figure 3(a)-(d) indicate that the SiGe layers are highly (111) oriented except the sample grown at $375{ }^{\circ} \mathrm{C}$. Such (111) orientation can be explained from the perspective of the appearance of the energetically stable plane $[21,25]$. Figure $3(\mathrm{e})-(\mathrm{h})$ indicate that the actual grains are smaller than the growth domains observed in Figure 2(a)(d), especially at high temperatures $\left(\geq 350^{\circ} \mathrm{C}\right)$. Figure 3(i) shows that the (111) fraction of SiGe increases with decreasing the growth temperature in the same manner as Ge (Al air exposure: $30 \mathrm{~min}$ ) [31]. The grain size of SiGe increases dramatically at temperatures below $350{ }^{\circ} \mathrm{C}$, whereas that of $\mathrm{Ge}$ increases gradually with decreasing the growth temperature. This means that low-temperature growth is essential for SiGe to suppress nucleation and facilitate lateral growth. This is likely attributed to the difficulty for SiGe in lateral growth because the SiGe composition has to match at the growth front. Thus, slow annealing in ALILE allowed for a SiGe layer having the highest (111) fraction and the largest grain size among the SGOIs formed at low temperatures $[37,39]$.

The plan-view compositional uniformity of the SiGe layer was evaluated using an 
energy dispersive X-ray spectrometer (EDX) equipped with a scanning electron microscopy (SEM). For clarifying a growth domain, the sample grown at $325{ }^{\circ} \mathrm{C}$ was employed after removing the unreacted a-SiGe layer by Secco etching. Figure 4(a)-(c) show that the SiGe composition is unbiased and uniform in a growth domain. The cross-sectional composition was measured using an analytical transmission electron microscope (TEM), FEI Tecnai Osiris operated at $200 \mathrm{kV}$, equipped with EDX and a high-angle annular dark-field scanning transmission electron microscopy (HAADF-STEM) system with a probe diameter of $\sim 1 \mathrm{~nm}$. As shown in Figure 4(d) and (e), a fluctuation of SiGe composition is present in a micro region; however, it keeps approximately the $\mathrm{Si} / \mathrm{Ge}$ ratio of $40: 60$, which is the same value as the initial a-SiGe layer. Such a uniform SiGe composition is likely attributed to the fact that the diffusion coefficients of $\mathrm{Si}$ and $\mathrm{Ge}$ in $\mathrm{Al}$ are almost equal [41].

The detailed cross-sectional structure of the $325^{\circ} \mathrm{C}$ annealed sample was investigated using TEM. TEM samples were prepared by the conventional focused ion beam method. Figure 4(f) shows a SiGe layer uniformly stacked on a substrate owing to layer exchange. Figure 4(g) shows a uniform bright contrast of the SiGe layer, indicating the single-crystal structure in this region without obvious defects. As representatively shown in Figure 4(h), some regions contained defects including twin boundaries (TBs) and stacking faults (SFs). The selected-area electron diffraction (SAED) pattern in Figure 4(i) proves a twinned SiGe structure and some streaking along the $\mathrm{SiGe}<111>$ direction, caused by planar defects in the 
SiGe $\{111\}$ planes. Because such defects are not observed in the elemental Ge layer formed by ALILE [31], those are attributed to the stress induced by the fluctuation of the SiGe composition shown in Figure 4(e). From the SAED pattern in Figure 4(i), the lattice spacing of $\mathrm{SiGe}\{111\}$ was determined to be $0.322 \mathrm{~nm}$, corresponding to a lattice constant of $0.557 \mathrm{~nm}$. According to Vegard's law, this lattice constant corresponds to the Si/Ge ratio of 63 to 37, which is almost consistent with the Raman and EDX studies.

In conclusion, we have demonstrated a large-grained, (111)-oriented SiGe layer with an intermediate composition using ALILE below $350{ }^{\circ} \mathrm{C}$. This means that ALILE can control the crystal orientation of SGOI in the entire composition. Since (111)-oriented SiGe works as epitaxial templates for various materials by tuning SiGe composition, this achievement is a key technology for integrating multiple functions monolithically on a device.

This work was financially supported by the JSPS KAKENHI (No. 26709019) and the Izumi Science and Technology Foundation. The authors are grateful to Dr. N. Fukata and Dr. D. Sekiba for assistance with Raman measurement and RBS analysis, respectively. Some experiments were conducted at the International Center for Young Scientists in NIMS. 


\section{REFERENCES}

[1] T. Tezuka, N. Sugiyama, S. Takagi, Appl. Phys. Lett. 79 (2001) 1798.

[2] H. Yang, D. Wang, H. Nakashima, Appl. Phys. Lett. 95 (2009) 1.

[3] Y. Tojo, R. Matsumura, H. Yokoyama, M. Kurosawa, K. Toko, T. Sadoh, M. Miyao, Appl. Phys. Lett. 102 (2013) 092102.

[4] G. Taraschi, A.J. Pitera, E.A. Fitzgerald, Solid. State. Electron. 48 (2004) 1297.

[5] N. Usami, W. Pan, K. Fujiwara, M. Tayanagi, K. Ohdaira, K. Nakajima, Sol. Energy Mater. Sol. Cells 91 (2007) 123.

[6] T. Matsui, C.W. Chang, T. Takada, M. Isomura, H. Fujiwara, M. Kondo, Sol. Energy Mater. Sol. Cells 93 (2009) 1100.

[7] Y. Kim, M. Takenaka, T. Osada, M. Hata, S. Takagi, Sci. Rep. 4 (2014) 4683.

[8] C.G. Littlejohns, M. Nedeljkovic, C.F. Mallinson, J.F. Watts, G.Z. Mashanovich, G.T. Reed, F.Y. Gardes, Sci. Rep. 5 (2015) 8288.

[9] T. Kawai, H. Yonezu, H. Yoshida, K. Pak, Appl. Phys. Lett. 61 (1992) 1216.

[10] R.R. Lieten, S. Degroote, K. Cheng, M. Leys, M. Kuijk, G. Borghs, Appl. Phys. Lett. 89 (2006) 252118.

[11] K. Hamaya, H. Itoh, O. Nakatsuka, K. Ueda, K. Yamamoto, M. Itakura, T. Taniyama, T. Ono, M. Miyao, Phys. Rev. Lett. 102 (2009) 137204.

[12] M. Suzuno, T. Koizumi, H. Kawakami, T. Suemasu, Jpn. J. Appl. Phys. 49 (2010) 04 DG16.

[13] W. Du, M. Suzuno, M. Ajmal Khan, K. Toh, M. Baba, K. Nakamura, K. Toko, N. Usami, T. Suemasu, Appl. 
Phys. Lett. 100 (2012) 152114.

[14] M. Isomura, K. Nakahata, M. Shima, S. Taira, K. Wakisaka, M. Tanaka, S. Kiyama, Sol. Energy Mater. Sol. Cells 74 (2002) 519.

[15] M. Tada, J.-H. Park, J.R. Jain, K.C. Saraswat, J. Electrochem. Soc. 156 (2009) D23.

[16] A.A. Shklyaev, V.I. Vdovin, V.A. Volodin, D.V. Gulyaev, A.S. Kozhukhov, M. Sakuraba, J. Murota, Thin Solid Films 579 (2015) 131.

[17] K. Tao, J. Wang, R. Jia, Y. Sun, Z. Jin, X. Lin, Scr. Mater. 107 (2015) 100.

[18] C.-Y. Tsao, Z. Liu, X. Hao, M.A. Green, Appl. Surf. Sci. 257 (2011) 4354.

[19] H. Watakabe, T. Sameshima, H. Kanno, T. Sadoh, M. Miyao, J. Appl. Phys. 95 (2004) 6457.

[20] K. Toko, H. Kanno, A. Kenjo, T. Sadoh, T. Asano, M. Miyao, Appl. Phys. Lett. 91 (2007) 042111.

[21] Z. Wang, J. Wang, L. Jeurgens, E. Mittemeijer, Scr. Mater. 55 (2006) 987.

[22] S. Peng, X. Shen, Z. Tang, D. He, Mater. Chem. Phys. 107 (2008) 431.

[23] O. Nast, T. Puzzer, L.M. Koschier, A.B. Sproul, S.R. Wenham, Appl. Phys. Lett. 73 (1998) 3214.

[24] M. Kurosawa, N. Kawabata, T. Sadoh, M. Miyao, Appl. Phys. Lett. 95 (2009) 132103.

[25] A. Sarikov, J. Schneider, J. Berghold, M. Muske, I. Sieber, S. Gall, W. Fuhs, J. Appl. Phys. 107 (2010) 114318.

[26] B.I. Birajdar, T. Antesberger, B. Butz, M. Stutzmann, E. Spiecker, Scr. Mater. 66 (2012) 550.

[27] Z. Wang, L. Gu, L.P.H. Jeurgens, F. Phillipp, E.J. Mittemeijer, Nano Lett. 12 (2012) 6126.

[28] R. Numata, K. Toko, N. Saitoh, N. Yoshizawa, N. Usami, T. Suemasu, Cryst. Growth Des. 13 (2013) 1767. 
[29] K. Toko, R. Numata, N. Saitoh, N. Yoshizawa, N. Usami, T. Suemasu, J. Appl. Phys. 115 (2014) 094301.

[30] S. Hu, A.F. Marshall, P.C. McIntyre, Appl. Phys. Lett. 97 (2010) 082104.

[31] K. Toko, M. Kurosawa, N. Saitoh, N. Yoshizawa, N. Usami, M. Miyao, T. Suemasu, Appl. Phys. Lett. 101 (2012) 072106 .

[32] K. Toko, R. Numata, N. Oya, N. Fukata, N. Usami, T. Suemasu, Appl. Phys. Lett. 104 (2014) 022106.

[33] J.-H. Park, K. Kasahara, K. Hamaya, M. Miyao, T. Sadoh, Appl. Phys. Lett. 104 (2014) 252110.

[34] H. Higashi, K. Kasahara, K. Kudo, H. Okamoto, K. Moto, J.-H. Park, S. Yamada, T. Kanashima, M. Miyao,

I. Tsunoda, K. Hamaya, Appl. Phys. Lett. 106 (2015) 041902.

[35] M. Gjukic, M. Buschbeck, R. Lechner, M. Stutzmann, Appl. Phys. Lett. 85 (2004) 2134.

[36] T. Iwasa, T. Kaneko, I. Nakamura, M. Isomura, Phys. Status Solidi 207 (2010) 617.

[37] M. Kurosawa, N. Kawabata, T. Sadoh, M. Miyao, ECS J. Solid State Sci. and Tech. 1 (2012) 144.

[38] T. Zhang, F. Ma, W. Zhang, Appl. Phys. Lett. 100 (2012) 071908.

[39] T. Sadoh, J. Park, R. Aoki, M. Miyao, Jpn. J. Appl. Phys. 55 (2016) 03CB01.

[40] C.-J. Lin, S.-Y. Wei, C.-C. Hsu, S.-M. Yu, W.-C. Sun, T.-S. Lin, et al., CrystEngComm. 17 (2015) 6269.

[41] C.A. Niedermeier, Z. Wang, E.J. Mittemeijer, Acta Mater. 72 (2014) 211.

[42] P.M. Mooney, F.H. Dacol, J.C. Tsang, J.O. Chu, Appl. Phys. Lett. 62 (1993) 2069. 


\section{Graphical abstract}

Orientation control of intermediate-composition SiGe on insulator by low-temperature Al-induced crystallization

Mitsuki Nakata, Kaoru Toko, Noriyuki Saitoh, Noriko Yoshizawa, Takashi Suemasu

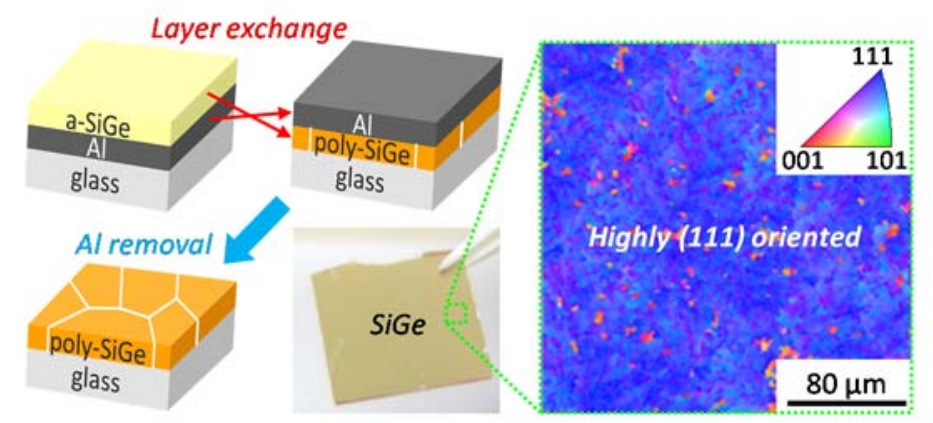

Al-induced layer exchange allows for a 99\% (111)-oriented SiGe thin film with an intermediate composition on a glass substrate. Slow annealing below $350{ }^{\circ} \mathrm{C}$ is a key for large-grain growth: it suppresses nucleation and facilitates lateral growth during the crystallization of the amorphous $\mathrm{Si}_{0.4} \mathrm{Ge}_{0.6}$ alloy. 

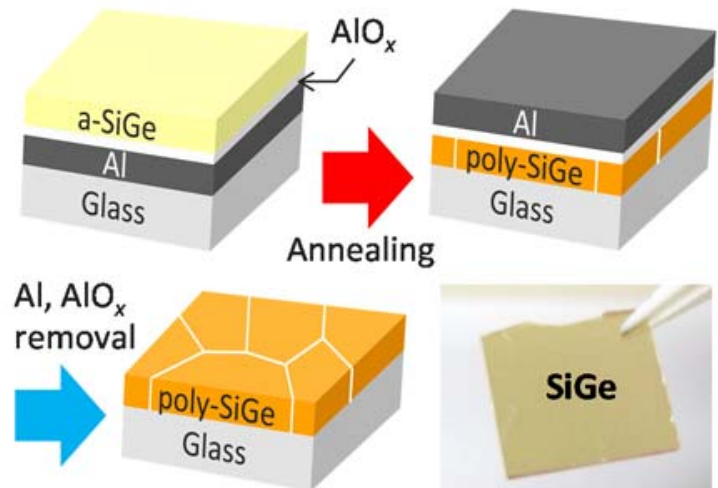

Figure 1. Schematic image of the sample preparation procedure. The photograph shows a representative resulting sample grown at $335^{\circ} \mathrm{C}$. 

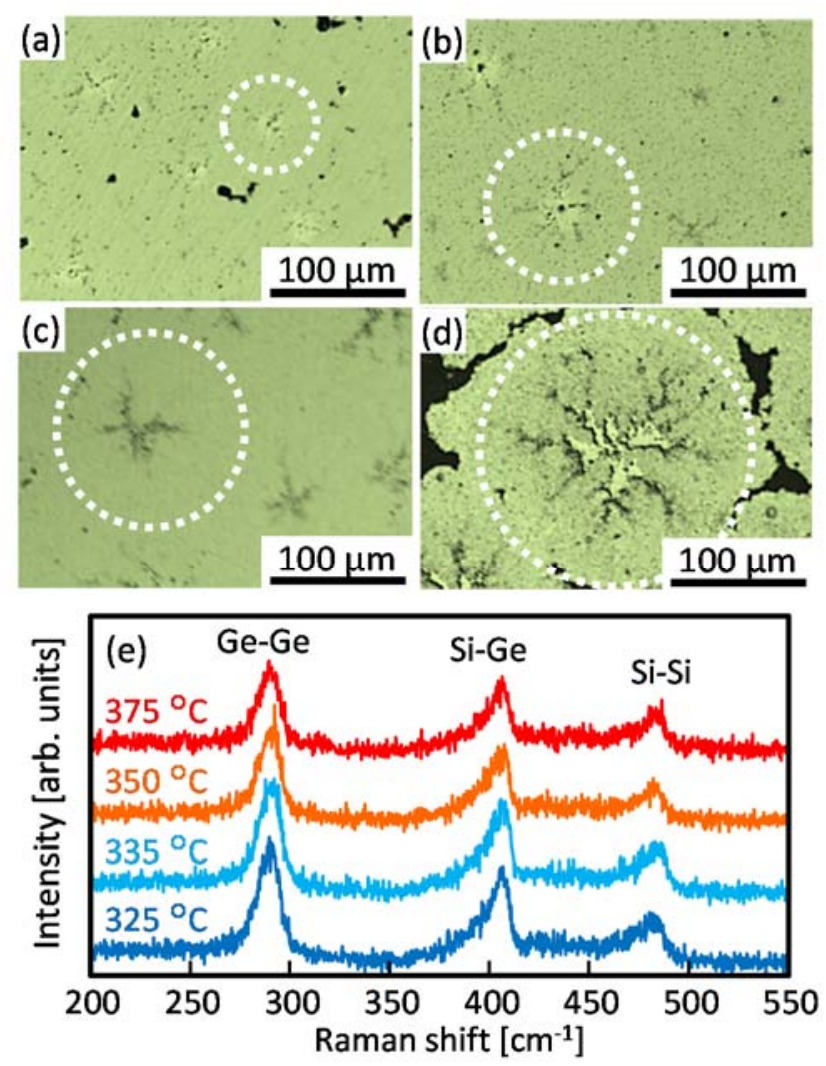

Figure 2. Nomarski optical micrographs of the samples annealed at (a) $375{ }^{\circ} \mathrm{C}$ for $30 \mathrm{~h}$, (b) $350{ }^{\circ} \mathrm{C}$ for $100 \mathrm{~h}$, (c) $335{ }^{\circ} \mathrm{C}$ for $150 \mathrm{~h}$, and (d) $325^{\circ} \mathrm{C}$ for $200 \mathrm{~h}$, where the dotted circles roughly indicate growth domains. (e) Raman scattering spectra for the samples shown in (a) -(d), indicating the crystallization of a-SiGe. 

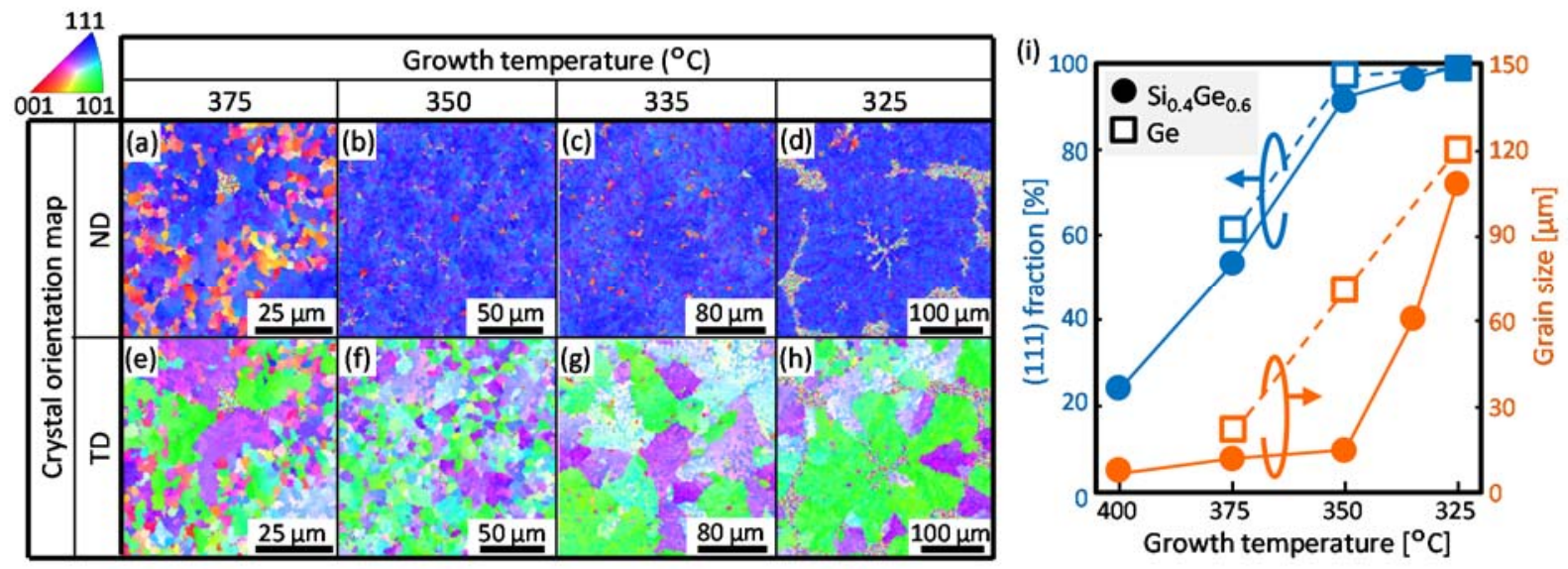

Figure 3. EBSD images of the SiGe layers grown at $325-375^{\circ} \mathrm{C}$, taken from the same region in the (a-d) normal direction (ND) and (e-h) transverse direction (TD) relative to the sample substrates. The coloration indicates crystal orientation, as shown in the legend. (i) (111) orientation fraction and the average grain size of the SiGe layers calculated from the EBSD data (closed circles), as a function of growth temperature. The data of Al-induced-crystallized Ge are shown for comparison (open squares). By definition, the (111) fraction included planes with tilts up to $15^{\circ}$ from the exact (111) plane; a grain was considered to be an area surrounded by random grain boundaries. 

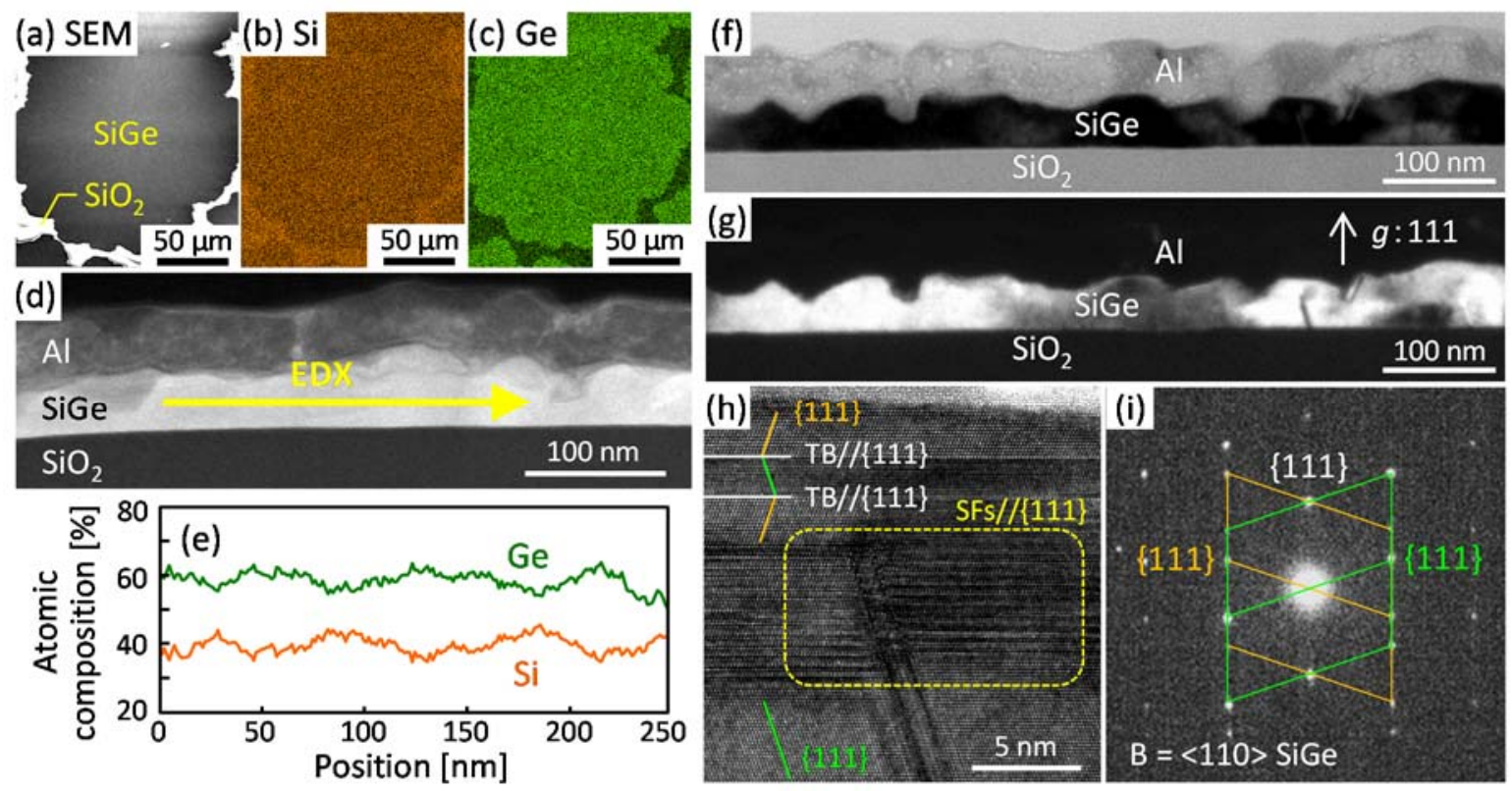

Figure 4. Characterization of the SiGe layer grown at $325{ }^{\circ} \mathrm{C}$. (a) Plane-view SEM image.

(b,c) EDX elemental maps of (b) Si and (c) Ge from the region shown in (a). (d) Cross-sectional HAADF-STEM image. (e) Elemental composition profile obtained by STEM-EDX line scan measurement along the arrow in (d). (f) Bright-field TEM image. (g) Dark-field TEM image using the SiGe $\{111\}$ plane reflection. (h) High-resolution lattice image showing a defect region in SiGe. (i) SAED pattern showing the SiGe $<110>$ zone axis, taken from the region shown in (h). 